\title{
PREVALENCE OF SENSORINEURAL HEARING LOSS IN CSOM WITH OR WITHOUT CHOLESTEATOMA (STUDY OF 100 CASES)
}

\author{
M. Mohamed Anwar1, Arun Magendran'2, A. Betty Janice ${ }^{3}$ \\ ${ }^{1}$ Associate Professor, Department of ENT, CMCH and RC. \\ ${ }^{2}$ Assistant Professor, Department of ENT, CMCH and RC. \\ ${ }^{3}$ CRRI.
}

\section{ABSTRACT}

\section{BACKGROUND}

Chronic Suppurative Otitis Media is an infectious disease, prevalent in developing countries especially in India and it is the common cause for hearing loss which can be prevented. The objective of the study is to know the prevalence of sensorineural hearing loss in CSOM with or without cholesteatoma.

\section{MATERIALS AND METHODS}

A prospective observational study of 100 cases of CSOM for convenience purpose was done for a period of 2 years. History taking, detailed clinical examination and audiometry were done and results tabulated.

\section{RESULTS}

In the present study 100 patients of CSOM were taken, out of which 30 patients had sensorineural component and 70 patients do not have sensorineural component. Out of 30 patients with sensorineural component, 16 were Males and 14 were Females. Similarly, 17 had disease in the left ear and 13 in the right ear. Patients with duration of disease for 16 - 20 years correspondingly, sensorineural component is more in the group (13) which is $43.34 \%$.

\section{CONCLUSION}

CSOM patients develop sensorineural component if the disease is not treated at the earliest, longer the duration stronger is the chance for getting the sensorineural component.

\section{KEYWORDS}

Sensorineural Hearing Loss, CSOM, Prevalence.

HOW TO CITE THIS ARTICLE: Anwar MM, Magendran A, Janice AB. Prevalence of sensorineural hearing loss in CSOM with or without cholesteatoma (study of 100 cases). J. Evolution Med. Dent. Sci. 2018;7(08):955-956, DOI: 10.14260/jemds/2018/218

\section{BACKGROUND}

CSOM is a common cause for hearing loss in developing countries, usually people present with mixed hearing loss of which sensorineural component needs to be investigated, some of the reasons for CSOM are poor hygiene, poor nutrition, pathologic bacteria, septic focus from nasopharynx and oropharynx. Usually round window membrane is not permeable, during chronic inflammation it becomes permeable and penetration of toxins from middle ear to inner ear which leads to sensorineural damage.

\section{MATERIALS AND METHODS (2014 to 2016)}

A prospective observational study of 100 cases of CSOM were included in the study for convenience for a period of 2 years.

\section{Inclusion Criteria}

- Patients should have CSOM for more than 5 years.

- $\quad$ Age from 15 - 45 years.

'Financial or Other Competing Interest': None.

Submission 10-01-2018, Peer Review 07-02-2018,

Acceptance 12-02-2018, Published 19-02-2018.

Corresponding Author:

Dr. Arun Magendran

9/1, Lawsons Road

Cantonment, Trichy-620001,

Tamilnadu.

E-mail: drarunmagendran@gmail.com

DOI: $10.14260 /$ jemds $/ 2018 / 218$

\section{Exclusion Criteria}

- $\quad$ Systemic problems (DM, HT, Hypothyroidism).

- Presbycusis, Ototoxicity.

- Meniere's disease.

- Sudden sensorineural loss.

- Complications of CSOM. These were excluded with detailed history taking, clinical examination and audiometry.

All patients were subjected to otomicroscopic examination and the type of CSOM is assessed (Tubotympanic or Atticoantral). All patients were subjected to Pure Tone Audiometry.

\section{RESULTS}

Out of 100 cases of CSOM about 30 patients presented with sensorineural component and 70 patients does not have sensorineural component.

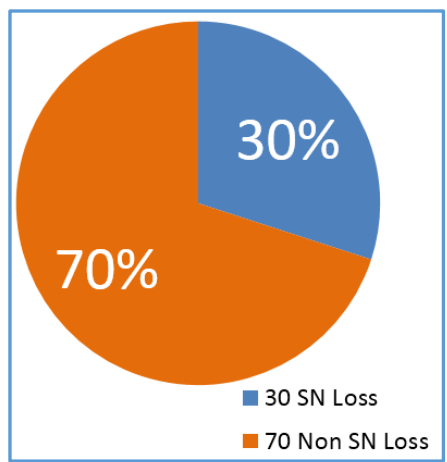

Sensorineural Loss in CSOM 
Out of 30 patients with sensorineural component in CSOM, 16 patients i.e. (53.33) were male and 14 patients i.e. (46.67) were female.

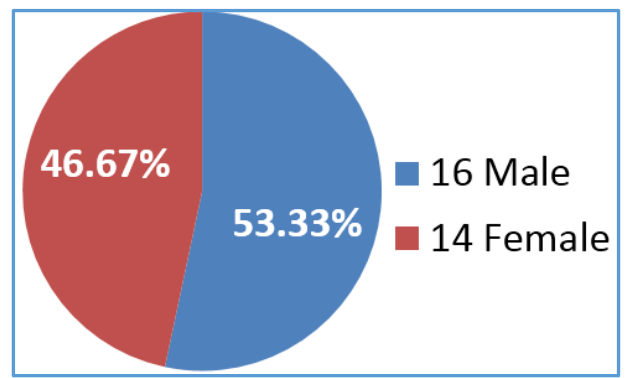

Sensorineural Component Sex Distribution

Out of 30 patients with CSOM with sensorineural component, 17 patients had disease in the left ear (i.e.) $56.67 \%$, while 13 patients in right ear (i.e.) $43.33 \%$.

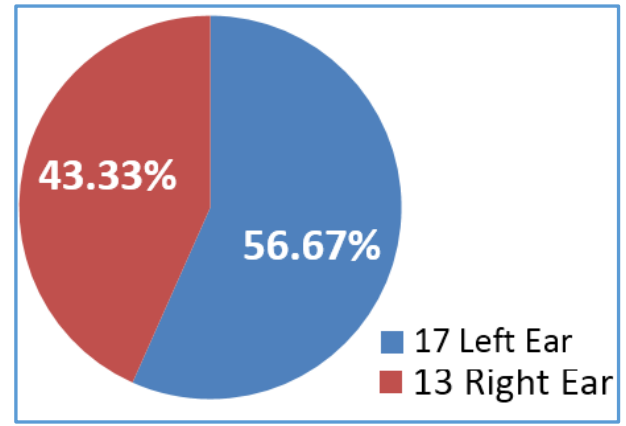

Sensorineural Component Side Distribution

Out of 30 patients with sensorineural component in CSOM, duration of disease was studied and tabulated in which maximum number of patients had disease for $16-20$ years correspondingly. SN component is more in this group (13).

\begin{tabular}{|c|c|c|}
\hline $\begin{array}{c}\text { Duration of } \\
\text { Disease }\end{array}$ & $\begin{array}{c}\text { No. of } \\
\text { Patients }\end{array}$ & $\begin{array}{c}\text { Prevalence of SN } \\
\text { Loss in \% }\end{array}$ \\
\hline $5-10$ yrs. & 5 & 16.66 \\
\hline $11-15$ yrs. & 8 & 26.67 \\
\hline $16-20$ yrs. & 13 & 43.34 \\
\hline$>20$ yrs. & 4 & 13.33 \\
\hline
\end{tabular}

Out of 30 patients with sensorineural component and CSOM, 17 patients had tubotympanic disease and 13 patients had atticoantral disease. Out of 30 patients of CSOM with sensorineural component more patients were in the age group between 31 - 40, about 14 patients (i.e.) 46.67\%. There were 4 patients in the age group between 11 - 20 yrs. (i.e.) $13.33 \%$; between 21 - 30 yrs. there were 8 patients (i.e.) $26.67 \%$ and more than 41 yrs. there were 4 patients (i.e.) $13.33 \%$.

\begin{tabular}{|c|c|c|}
\hline Age Group & No. of Patients & Percentage \\
\hline $11-20$ & 4 & 13.33 \\
\hline $21-30$ & 8 & 26.67 \\
\hline $31-40$ & 14 & 46.67 \\
\hline$>41$ & 4 & 13.33 \\
\hline
\end{tabular}

\section{DISCUSSION}

In our study, $30 \%$ patients i.e. (30 out of 100) of CSOM had sensorineural component. In a study conducted by Kamaljit(1) Kaur et al (2003), the total number of patients with sensorineural component was $24 \%$ and Levine(2) (1989) was $37.2 \%$.

In our study overall age distribution was from 15 to 45 yrs., majority of patients with sensorineural component were between 31 - 40 yrs. There were 14 patients (46.67\%), mean age 32. According to Ahmed Raquib(3) et al (2009) mean age was 31.1 and Kirtane ${ }^{(4)}$ et al (1985) mean age was 24.

In our study 13 patients who had CSOM for 16 to $20 \mathrm{yrs}$. had sensorineural component, while shows longer the duration stronger is the tendency to develop sensorineural component. Kirtane ${ }^{(4)}$ MV et al (1985) studies show longstanding otorrhoea, higher is the incidence for sensorineural component.

In our study out of 30 patients of CSOM with sensorineural component, 17 patients were of tubotympanic type and 13 patients were atticoantral type according to Vartiainen(5) (1987), Levine(2) (1989) and Cusimano(6) (1989) shows increase is seen in atticoantral type.

According to Vartiainen(5) (1987) study of 873 chronically infected cases showed high frequency hearing loss, more prevalent in chronic cases. Similarly, Huang(7) et al (1990) studied the potential cytotoxic effects of two inflammatory mediators, endotoxin and free radicals concluded that inflammatory mediators are cytotoxic to hair cells.

\section{CONCLUSION}

Chronic Suppurative Otitis Media patients develop sensorineural component if the disease is not treated at the earliest, longer the duration stronger is the chance for getting the sensorineural component. Usually, the inflammatory mediators pass through the round window membrane and cause damage to hair cells. So, treat the condition earlier and prevent irreparable hearing loss.

\section{REFERENCES}

[1] Kaur K, Sonkhya N, Bapna AS. Chronic suppurative otitis media and sensorineural hearing loss: is there a correlation? Indian J Otolaryngol Head Neck Surg 2003;55(1):21-4.

[2] Levine BA, Shelton C, Berliner KI, et al. Sensorineural loss in chronic otitis media, is it clinically significant? Arch Otolaryngol Head Neck Surg 1989;115(7):814-6.

[3] Raquib A, Taous A, Haque R. Sensorineural component in chronic suppurative otitis media. Bangladesh Journal of Otorhinolaryngology 2009;15(2):69-74.

[4] Kirtane MV, Merchant SN, Raje AR, et al. Sensorineural hearing loss in chronic otits media-a-statistical evaluation. J Post Med 1985;31(4):183-6.

[5] Vartiainen E, Karjalainen S. Factors influencing sensorineural hearing loss in chronic otitis media. Am J Otolaryngol 1987;8(1):13-5.

[6] Cusimano F, Cocita VC, D'Amico A. Sensorineural hearing loss in chronic otitis media. J Laryngol Otol 1989;103(2):158-63.

[7] Huang M, Duion D. Outer hair cells as potential targets of inflammatory mediators. Ann Otol Rhinol Laryngol Suppl 1990;148:35-8. 